\title{
Observations of marine cold-air outbreaks: A comprehensive data set of airborne and dropsonde measurements from the Springtime Atmospheric Boundary Layer Experiment (STABLE)
}

\author{
Janosch Michaelis $^{1}$, Amelie U. Schmitt ${ }^{2}$, Christof Lüpkes ${ }^{1}$, Jörg Hartmann ${ }^{1}$, Gerit Birnbaum ${ }^{1}$, and \\ Timo Vihma ${ }^{3,4}$ \\ ${ }^{1}$ Alfred-Wegener-Institute Helmholtz Center for Polar and Marine Research, Bremerhaven, Germany \\ ${ }^{2}$ Meteorological Institute, Center for Earth System Research and Sustainability (CEN), Universität Hamburg, Hamburg, \\ Germany \\ ${ }^{3}$ Finnish Meteorological Institute, Helsinki, Finland \\ ${ }^{4}$ The University Centre in Svalbard, Longyearbyen, Norway
}

Correspondence: Janosch Michaelis (janosch.michaelis@awi.de)

\begin{abstract}
In March 2013, the Springtime Atmospheric Boundary Layer Experiment (STABLE) was carried out in the region of Fram Strait and over Svalbard to investigate atmospheric convection and boundary layer modifications due to interactions between sea ice, atmosphere, and open water. A major goal was the observation of marine cold-air outbreaks (MCAOs), which are typically characterised by a transport of very cold air masses from the ice-covered ocean over a relatively warm water days within a period of a strongly northward shifted sea ice edge north of Svalbard and thus with an unusually large Whaler's Bay Polynya. The observations mainly consisted of in situ measurements from airborne instruments and of measurements by dropsondes. Here, we present the corresponding data set from, in total, 15 aircraft vertical profiles and 22 dropsonde releases. Besides an overview on flight patterns and instrumentation, we provide a detailed presentation of the individual quality-processing mechanisms, which ensure that the data can be used, for example, for model validation. A few remarks are also given on data quality and on some characteristics of the MCAOs based on the quality-processed data. All 37 data series are published in the World Data Center PANGAEA (Lüpkes et al., 2021a, https://doi.pangaea.de/10.1594/PANGAEA.936635).
\end{abstract}

\section{Introduction}

During marine cold-air outbreaks (MCAOs), cold air masses typically originating from the sea ice covered ocean are advected over a relatively warm water surface, which can result in moderate or strong convection depending on the season. In the highlatitudes, MCAOs represent one of the strongest events of atmosphere-ocean interaction (Brümmer, 1996) and thus they often affect local and regional weather conditions, for example, by promoting polar low formation (Rasmussen, 2003). MCAOs are accompanied by a large variety of small-scale processes (e.g., roll- and cellular convection, cloud radiative processes, phase changes of water, local and non-local turbulence) and, in turn, these processes depend on many different preconditions (e.g., sea ice structure and concentration, moisture content above the temperature inversion), which complicates their exact represen- 
https://doi.org/10.5194/essd-2021-341

Preprint. Discussion started: 3 November 2021

(c) Author(s) 2021. CC BY 4.0 License.

\section{(c) (1)}

tation in numerical weather prediction and climate models (e.g., Pithan et al., 2018). Observational and modelling studies on the respective processes can be found in, for example, Brümmer et al. (1992); Lüpkes and Schlünzen (1996); Brümmer (1997); Hartmann et al. (1997); Brümmer (1999); Gryanik and Hartmann (2002); Liu et al. (2006); Gryschka et al. (2008); Chechin et al. (2013); Gryschka et al. (2014); Chechin and Lüpkes (2017), and more general reviews in, for example, Etling and Brown (1993); Brümmer and Pohlmann (2000); Lüpkes et al. (2012) and Vihma et al. (2014).

Some projections suggest a future weakening of MCAOs and, correspondingly, a weaker or reduced polar low development by increased sea ice loss in their source region (e.g., Kolstad and Bracegirdle, 2008; Zahn and von Storch, 2010; Landgren et al., 2019). For some regions, such a development might be an already ongoing process: the Fram Strait region, which is characterised by a high frequency of strong Northern Hemisphere MCAO events (Brümmer and Pohlmann, 2000; Fletcher et al., 2016), is marked by a stronger than average retreat in Arctic sea ice extent (Cavalieri and Parkinson, 2012). As shown by Tetzlaff et al. (2014) and Tetzlaff (2016), it is also a prominent example of an already ongoing poleward movement of an MCAO source region. However, in 2013, the MCAO development was - at least in its northern part - extreme by a northward shift of the ice edge and an unusually large width of the Whaler's Bay Polynya north of Svalbard (Tetzlaff et al., 2014, their Fig. 1), which calls for further research to better understand the future trends. Tetzlaff et al. (2014) and Tetzlaff (2016) used data from the aircraft campaign Springtime Atmospheric Boundary Layer Experiment (STABLE) led by the German AlfredWegener-Institut. It took place north and west of Svalbard in March 2013. MCAOs were investigated on four days using in situ and remote sensing instrumentation of the research aircraft Polar 5 as well as dropsondes released from the aircraft.

The aim of this paper is to provide a detailed presentation of the measurements related to the MCAOs observed during STABLE. The corresponding data set, which is accessible on the World Data Center PANGAEA (Lüpkes et al., 2021a, https://doi.pangaea.de/10.1594/PANGAEA.936635) consists of measurements from 15 vertical aircraft profiles (Table 1) and 20 dropsondes (Table 2) over the marginal sea ice zone (MIZ) as well as over the open ocean region nearly along the direction of the lower atmospheric flow in the considered MCAOs (see Fig. 1). Data from two additional dropsondes, which were released to investigate spatial and temporal differences of the observations, are also included (see also Table 2). All data were quality-processed, where for the dropsonde data we used the Atmospheric Sounding Processing Environment software (ASPEN, see Martin and Suhr, 2021).

Section 2 deals with a brief overview of the campaign STABLE, including the large-scale weather situations causing the MCAOs, and with the aircraft instrumentation. In Sect. 3, we explain the quality-processing of the data. Section 4 provides some remarks on data quality and statistics and Sect. 5 on some characteristics of the MCAOs based on the quality-processed data. Finally, a data availability statement is made in Sect. 6, and conclusions are drawn in Sect. 7.

\section{Materials and methods}

We present a data set that was collected during the campaign STABLE in the Fram Strait region north and west of Svalbard on 4, 6, 7, and 26 March 2013. The large-scale weather patterns on those days promoted the formation of strong MCAOs. The observations on 4, 6, and 7 March all concentrated on the same MCAO episode. In the course of 3 March, northerly winds 
https://doi.org/10.5194/essd-2021-341

Preprint. Discussion started: 3 November 2021

(c) Author(s) 2021. CC BY 4.0 License.

Table 1. Overview of all aircraft ascents and descents performed mostly upwind of the sea ice margin on 4, 6, and 7 March $2013 .^{a}$

\begin{tabular}{lcccc}
\hline Date & Flight leg & Start time (UTC) & Mean fetch $(\mathrm{km})$ & Link to data series in PANGAEA \\
\hline \multirow{3}{*}{ 4 March } & T1 & $12: 03: 32$ & -179 & https://doi.pangaea.de/10.1594/PANGAEA.936639 \\
& T2 & $12: 05: 40$ & -178 & https://doi.pangaea.de/10.1594/PANGAEA.936645 \\
& T3 & $12: 53: 55$ & -290 & https://doi.pangaea.de/10.1594/PANGAEA.936646 \\
& T4 & $12: 56: 20$ & -289 & https://doi.pangaea.de/10.1594/PANGAEA.936647 \\
& T5 & $13: 42: 55$ & -404 & https://doi.pangaea.de/10.1594/PANGAEA.936648 \\
& T6 & $13: 46: 45$ & -403 & https://doi.pangaea.de/10.1594/PANGAEA.936650 \\
& T7 & $15: 04: 19$ & -64 & https://doi.pangaea.de/10.1594/PANGAEA.936651 \\
\hline \multirow{3}{*}{ 6 March } & T1 & $12: 19: 08$ & -106 & https://doi.pangaea.de/10.1594/PANGAEA.936655 \\
& T2 & $12: 24: 15$ & -105 & https://doi.pangaea.de/10.1594/PANGAEA.936656 \\
& T3 & $13: 09: 40$ & -217 & https://doi.pangaea.de/10.1594/PANGAEA.936660 \\
& T4 & $13: 13: 52$ & -215 & https://doi.pangaea.de/10.1594/PANGAEA.936661 \\
& T5 & $13: 48: 37$ & -296 & https://doi.pangaea.de/10.1594/PANGAEA.936663 \\
\hline 7 March & T6 & 13:52:48 & -297 & https://doi.pangaea.de/10.1594/PANGAEA.936664 \\
& T7 & $15: 05: 42$ & 33 & https://doi.pangaea.de/10.1594/PANGAEA.936665 \\
\hline
\end{tabular}

${ }^{a}$ The mean fetch along the flight tracks denotes the mean distance to the sea ice edge during the flight legs with negative/positive values denoting flights over sea ice/open water. These distances were determined along the $5^{\circ} \mathrm{E}$ (4 March), $2.5^{\circ} \mathrm{E}$ (6 March), and $2^{\circ} \mathrm{E}$ (7 March) meridians, respectively.

and thus a strong off-ice flow had developed in the lower troposphere over Fram Strait between a low pressure system east of Svalbard and a strong high pressure system over Greenland. These large-scale weather conditions more or less persisted for another four days although on 7 March in the southern part the lower tropospheric flow slightly turned to northwest (Fig. 1a-1c). On 8 March, the MCAO weakened due to a high pressure ridge that moved to the region west of Svalbard. The satellite images in Fig. 1 show that especially on 26 March the MCAO affected the Whaler's Bay Polynya. On that day, the flow had almost a northeast-southwest orientation (Fig. 1d) and was thus directed along the corresponding axis of the polynya. The corresponding large-scale weather pattern was characterised by a low pressure system located at the southern tip of Svalbard, which had developed in the previous night.

The measurements during STABLE were performed with the Polar 5 research aircraft, a Basler BT- $67^{1}$. The following description of flight patterns and instrumentation is partly based on Tetzlaff et al. (2014) and Tetzlaff (2016). Apart from observing MCAOs, an additional topic of STABLE was the measurement of atmospheric boundary layer (ABL) convection over leads in sea ice (mean and turbulent quantities). These measurements are described in detail by Tetzlaff et al. (2015), Tetzlaff (2016), and Michaelis et al. (2021), and the corresponding data can be found in Lüpkes et al. (2021b).

\footnotetext{
${ }^{1}$ for more information, see https://www.awi.de/en/expedition/flugzeuge/polar-5-6/artikel/retrofitted-into-a-polar-research-aircraft.html
} 
Table 2. Overview of all dropsondes released on 4, 6, 7, and 26 March $2013 .^{a}$

\begin{tabular}{|c|c|c|c|c|}
\hline Date & Dropsonde No. & Release time (UTC) & Mean fetch $(\mathrm{km})$ & Link to data series in PANGAEA \\
\hline \multirow{5}{*}{4 March } & D1 & $15: 19: 38$ & -5 & https://doi.pangaea.de/10.1594/PANGAEA.936612 \\
\hline & D2 & $15: 31: 19$ & 48 & https://doi.pangaea.de/10.1594/PANGAEA.936613 \\
\hline & D3 & $15: 42: 07$ & 104 & https://doi.pangaea.de/10.1594/PANGAEA.936614 \\
\hline & D4 & $15: 53: 16$ & 161 & https://doi.pangaea.de/10.1594/PANGAEA.936615 \\
\hline & D5 & $16: 04: 54$ & 214 & https://doi.pangaea.de/10.1594/PANGAEA.936616 \\
\hline \multirow{5}{*}{6 March } & D1 & $15: 16: 25$ & 57 & https://doi.pangaea.de/10.1594/PANGAEA.936617 \\
\hline & D2 & $15: 28: 02$ & 109 & https://doi.pangaea.de/10.1594/PANGAEA.936618 \\
\hline & D3 & $15: 38: 02$ & 165 & https://doi.pangaea.de/10.1594/PANGAEA.936619 \\
\hline & D4 & $15: 49: 04$ & 220 & https://doi.pangaea.de/10.1594/PANGAEA.936620 \\
\hline & $\mathrm{D}^{b}$ & $16: 06: 44$ & 92 & https://doi.pangaea.de/10.1594/PANGAEA.936621 \\
\hline \multirow{3}{*}{7 March } & D1 & $15: 06: 41$ & 49 & https://doi.pangaea.de/10.1594/PANGAEA.936622 \\
\hline & D2 & $15: 17: 51$ & 114 & https://doi.pangaea.de/10.1594/PANGAEA.936623 \\
\hline & D3 & $15: 46: 46$ & 203 & https://doi.pangaea.de/10.1594/PANGAEA.936624 \\
\hline \multirow{9}{*}{26 March } & $\mathrm{D} 1^{c}$ & $11: 54: 02$ & -59 & https://doi.pangaea.de/10.1594/PANGAEA.936625 \\
\hline & D2 & $14: 13: 31$ & -59 & https://doi.pangaea.de/10.1594/PANGAEA.936626 \\
\hline & D3 & 14:30:09 & 35 & https://doi.pangaea.de/10.1594/PANGAEA.936627 \\
\hline & D4 & $14: 42: 20$ & 107 & https://doi.pangaea.de/10.1594/PANGAEA.936628 \\
\hline & D5 & $14: 52: 16$ & 166 & https://doi.pangaea.de/10.1594/PANGAEA.936629 \\
\hline & D6 & $15: 01: 26$ & 223 & https://doi.pangaea.de/10.1594/PANGAEA.936630 \\
\hline & D7 & $15: 10: 23$ & 277 & https://doi.pangaea.de/10.1594/PANGAEA.936631 \\
\hline & D8 & 15:18:03 & 324 & https://doi.pangaea.de/10.1594/PANGAEA.936632 \\
\hline & D9 & $15: 27: 28$ & 381 & https://doi.pangaea.de/10.1594/PANGAEA.936633 \\
\hline
\end{tabular}

\footnotetext{
${ }^{a}$ The mean fetch denotes the mean distance to the sea ice edge along the flight track for each dropsonde. For 4, 6, and 7 March, these distances were determined along the $5^{\circ} \mathrm{E}$ (4 March), $2.5^{\circ} \mathrm{E}$ ( $6 \mathrm{March}$ ), and $2^{\circ} \mathrm{E}$ (7 March) meridians, respectively. For $26 \mathrm{March}$, the values refer to the sea ice edge at $80.9^{\circ} \mathrm{N}$ and $17^{\circ} \mathrm{E}$, which approximately marks the northeasternmost extension of the Whaler's Bay Polynya on that day (see Fig. 1d). ${ }^{b}$ This dropsonde was released at the same latitude as dropsonde D4 from the same day but more to the west and with shorter fetch, and ${ }^{c}$ this dropsonde was released almost at the same position as dropsonde D2 from the same day but approximately 2:15 h earlier (see also Fig. 1).
}

\subsection{Flight patterns}

All research flights of typically 5-6 hours duration started and ended at the airport of Longyearbyen (see also Fig. A1 in Appendix A), and the measurements described in this paper took place between approximately 12:00 and 16:00 UTC on each day. Horizontally, the measurements covered an area between approximately $78-84^{\circ} \mathrm{N}$ and $-5-25^{\circ} \mathrm{E}$ (Fig. 1). Basically, the flights were organised as follows. Especially over the open ocean region with strong convective rolls and related clouds, flights were carried out at constant altitude at about $3000 \mathrm{~m}$, while dropsondes were released. Prior to the release of the dropsondes, 
(a)
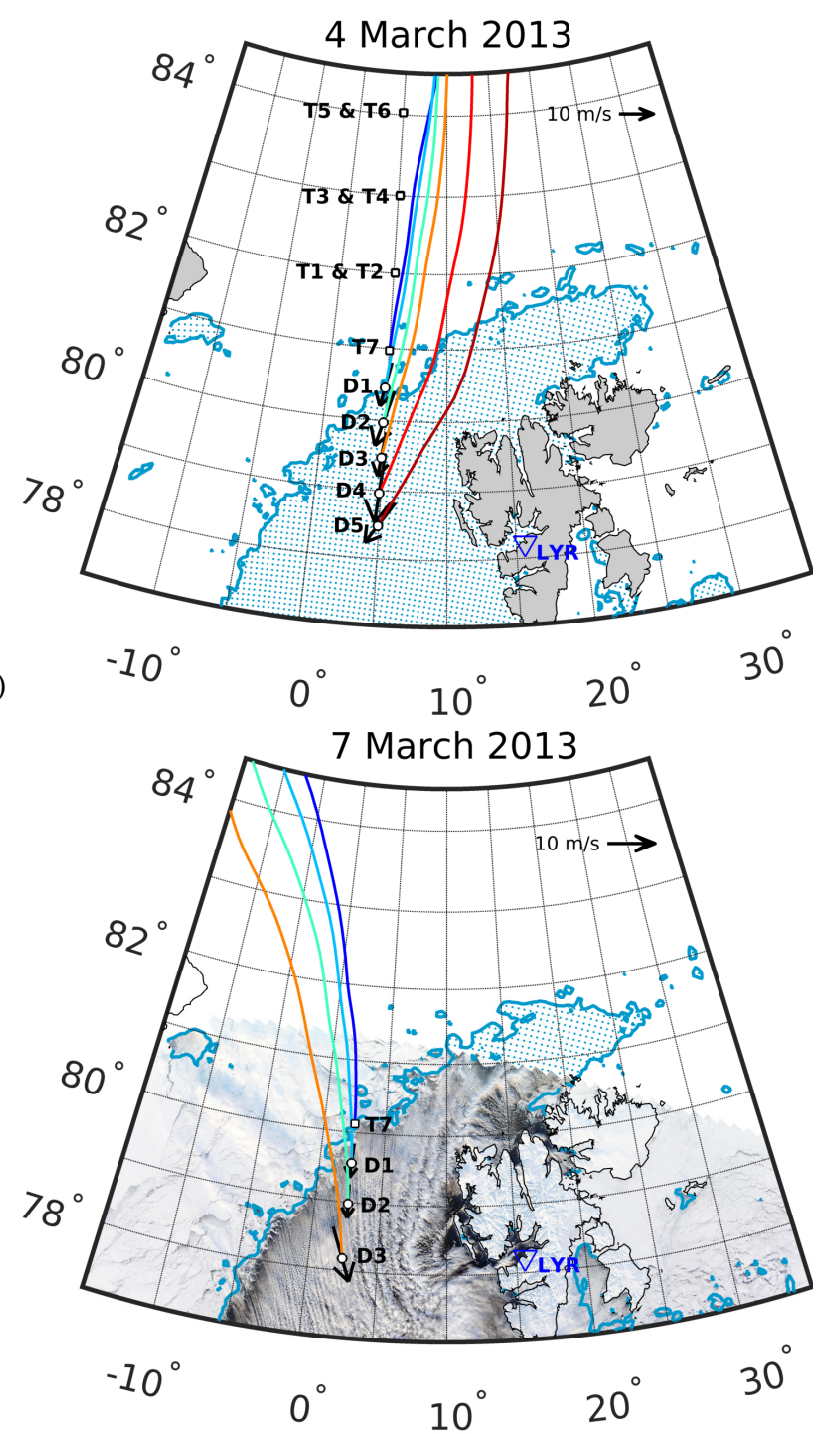

(b)
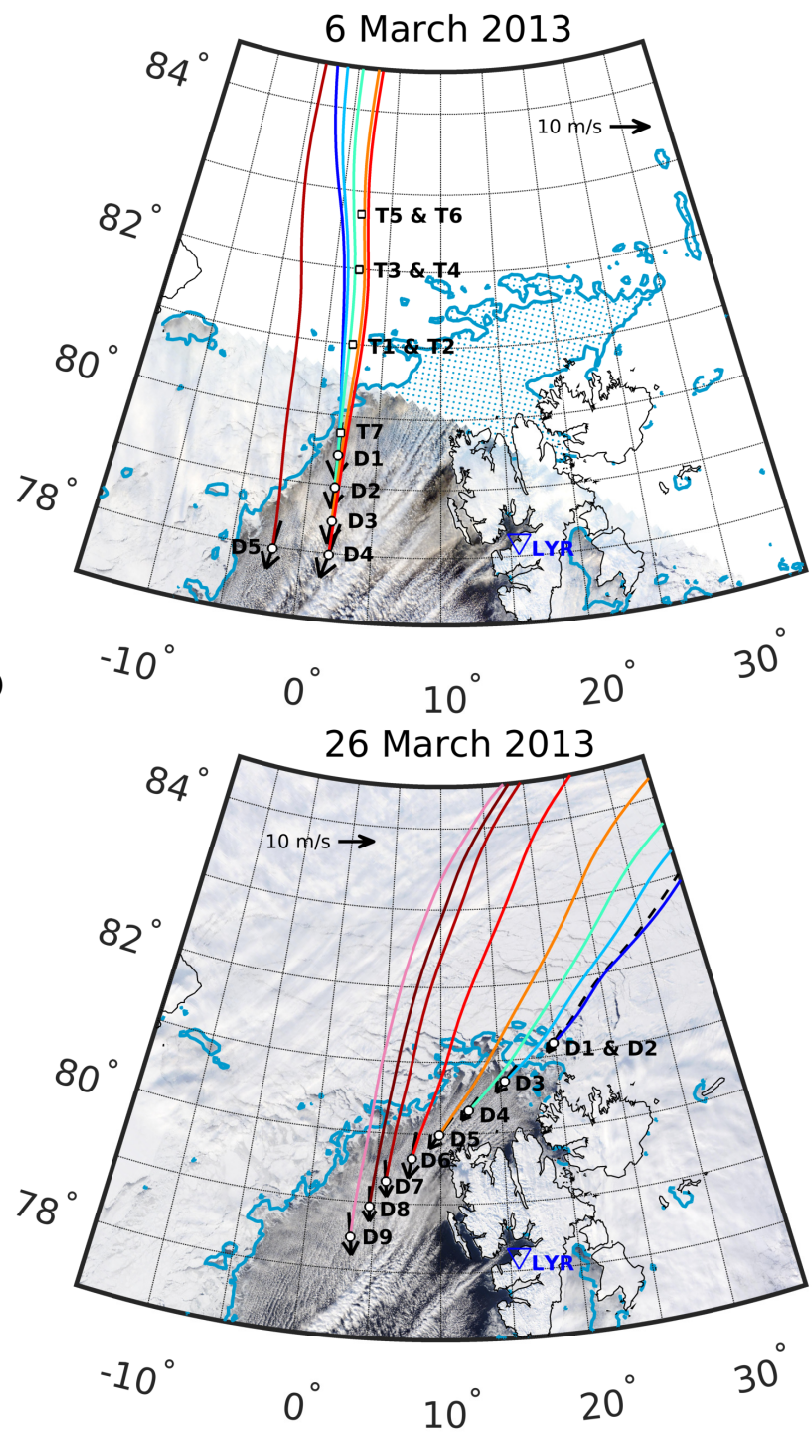

Figure 1. Ice edge based on a $70 \%$ threshold value of the ice concentration (derived with the ARTIST Sea Ice algorithm for the Advanced Microwave Scanning Radiometer 2, see Spreen et al., 2008) during MCAOs on (a) 4 March, (b) 6 March, (c) 7 March, and (d) 26 March 2013. The arrows denote the vertically ABL-averaged wind at the positions of the dropsondes listed in Table 2 (circles). Squares in (a)-(c) denote the locations of the aircraft profiles listed in Table 1. Coloured lines are backward-trajectories obtained with the Hybrid SingleParticle Lagrangian Integrated Trajectory transport and dispersion model (Draxler and Rolph, 2010) at $10 \mathrm{~m}$ height from the positions of the dropsondes and of the the southernmost aircraft vertical profiles for 4, 6, and 7 March. Backgrounds of (b)-(d) are the corresponding MODIS visible images at 13:10 UTC, 12:15 UTC, and 12:45 UTC, respectively (data from https://lance.modaps.eosdis.nasa.gov/modis/). Blue triangles mark the location of Longyearbyen airport. Modified based on Tetzlaff et al. (2014) and Tetzlaff (2016). 
flight sections were flown north of the sea ice edge, mainly low-level sections in the ABL but some of them also at $3000 \mathrm{~m}$. These sections were interrupted at some points by ascents and descents to measure the vertical structure of the ABL. Cloud cover decreased during all flights towards North, while in turn the sea ice concentration increased to more than 90-95\%. The data set we describe here was gained from the ascents and descents as well as from the dropsondes released from approximately $3000 \mathrm{~m}$ height (see Fig. 1 and Tables 1-2).

For both 4 and 6 March, the data set consists of measurements from seven ascents and descents over the MIZ northwest of Svalbard (T1-T7) and of five dropsondes (D1-D5). On both days, the aircraft profiles T1-T6 were performed between about $40 \mathrm{~m}$ height and an altitude of 500-1000 m, which was above the shallow ABL. For these flight legs, the lower limits of the profiles were mostly determined by the low-level cloud conditions over sea ice. The remaining flight legs T7 represent ascents performed up to almost $3000 \mathrm{~m}$. For 7 March, measurements are available only from one ascent over the sea ice edge (T1) and from three dropsondes (D1-D3). For 26 March, only dropsonde measurements are included (D1-D9).

All dropsondes were released mainly over the open ocean region between the sea ice edge and a few $100 \mathrm{~km}$ downwind. Only three sondes were used north of the sea ice edge and thus over the sea ice covered region (D1 from 4 March as well as D1 and D2 from 26 March). On 4, 6, and 7 March, the ascents, descents, and dropsonde measurements were performed along a certain meridian and the meridional orientation of the flight patterns roughly corresponded with the main ABL flow direction in the MCAO as shown by the ABL-averaged winds at the dropsondes' positions (Fig. 1a-1c). The corresponding MODIS visible images (for 6 and 7 March) denote that the main orientation of the cloud streets agreed well with the ABL-averaged winds on 7 March. However, a small shift is shown for 6 March, which might be due to the $3 \mathrm{~h}$ time difference between the satellite image and the dropsonde measurements (Fig. 1b). The MCAO observed on 26 March originated over the Whaler's Bay Polynya so that the dropsonde measurements were performed along the main MCAO orientation from northeast to southwest (Fig. 1d).

\subsection{Instrumentation}

\subsubsection{Aircraft}

The data from the aircraft vertical profiles consist of high-frequency meteorological measurements as well as GPS- and Internal Navigation System (INS)-based measurements for position and altitude. Altitude is also provided based on the measured atmospheric static pressure. The corresponding offset in the original data due to the reference pressure at departure was corrected using radar altimeter measurements during low-level flight legs between the vertical profiles. Differences between pressure and GPS height are explained in more detail in Sect. 4. Meteorological quantities were measured by instruments installed in and at the aircraft's nose-boom. Air pressure was measured with a five-hole probe, where the individual pressure components were then used to derive horizontal and vertical wind components. Note that we provide here only mean meteorological quantities since the systematic determination of turbulent fluxes would have required different flight patterns. Vertical wind is only available as a deviation from the average value during horizontal flight sections (see also Ehrlich et al., 2019) so that this quantity is also not provided in the final airborne data set. Temperature was measured with a Pt100 resistance thermometer, and relative humidity with a dew point mirror. Pressure and temperature sensors responded fast enough to obtain a recording frequency of 
$100 \mathrm{~Hz}$, whereas for humidity it is lower $(1 \mathrm{~Hz})$. In the final, quality-controlled data set, all measurements are provided with $100 \mathrm{~Hz}$ resulting in a vertical resolution of approximately $5 \mathrm{~cm}$. Measurement accuracies are determined as $\pm 0.1 \mathrm{hPa}$ for pressure, $\pm 0.01 \mathrm{~K}$ for temperature, $\pm 0.4 \%$ for relative humidity, and $\pm 0.2 \mathrm{~ms}^{-1}$ for the horizontal wind components (Hartmann et al., 2018). Note that especially the accuracy of humidity measurements depends on environmental conditions and that the accuracy for the wind components is valid rather for horizontal flight legs and might be less during vertical profiles due to a different pressure field surrounding the aircraft (Hartmann et al., 2018). More details on the aircraft's instrumentation, the individual sensors, calibration procedures, and on the accuracies of the resulting data are provided in Hartmann et al. (2018) and Ehrlich et al. (2019, their Sect. 3.1).

\subsubsection{Dropsondes}

The dropsondes of type RD93 manufactured by Vaisala were launched from the aircraft using the Airborne Vertical Atmosphere Profiling System (AVAPS, software version 1.7.1, see Ikonen et al., 2010) in its lite version, which can process one dropsonde at the same time (Vaisala, 2009). In the following, we briefly summarise the main properties of both the sondes and AVAPS based on the more detailed information given by Hock and Franklin (1999), Vaisala (2009), and Ikonen et al. (2010). Each sonde has a diameter of $7 \mathrm{~cm}$, is $41 \mathrm{~cm}$ long, weighs about $390 \mathrm{~g}$, and is equipped with temperature, humidity, and pressure sensors. Position, height, as well as wind speed and direction are derived from a GPS module that can track up to 12 satellites simultaneously. Pressure, temperature, and humidity measurements are collected by the AVAPS every $0.5 \mathrm{~s}$ and GPS-derived wind every $0.25 \mathrm{~s}$. In addition, the number of satellites used for the individual GPS-based measurements and the wind error are reported. Considering the sondes' fall rates of about $-10 \mathrm{~ms}^{-1}$ during STABLE, a spatial resolution of approximately $2.5 \mathrm{~m}$ was obtained for wind and $5 \mathrm{~m}$ for the other meteorological quantities. Measurement accuracies are indicated by the manufacturer as $0.2 \mathrm{~K}$ for temperature, $0.4 \mathrm{hPa}$ for pressure, $2 \%$ for relative humidity, and $0.5 \mathrm{~ms}^{-1}$ for the horizontal wind speed (Vaisala, 2009). Following the remarks given by Hock and Franklin (1999), these values might be larger in non-laboratory conditions. For an older version of the Vaisala GPS dropsondes, they estimated measurement errors of $0.2 \mathrm{~K}$ for temperature, $1.0 \mathrm{hPa}$ for pressure, $<5 \%$ for relative humidity, and $0.5-2 \mathrm{~ms}^{-1}$ for the horizontal wind speed (Hock and Franklin, 1999, their Table 3). The measurements transmitted by each dropsonde were stored by the AVAPS as ascii-formatted text files, for which we then applied quality-processing mechanisms using ASPEN (see Sect. 3.2).

\section{Quality-processing of the data}

For both airborne and dropsonde measurements, several quality-processing steps were performed to obtain reliable and highquality data sets to be used, for example, for model validation.

\subsection{Quality-processing of airborne measurements}

Post-flight quality-controlling for the airborne measurements included the interpolation of GPS- and INS-data to the time of the sensors installed at the turbulence nose-boom as well as the removal of outliers within the data series if required. Air pressure 
data were corrected for the influence of the aircraft and air temperature data for adiabatic heating. The latter correction depends on the aircraft's speed, which is related to the dynamic pressure so that the following formula was applied:

$T=\left(T e_{N}+273.15 \mathrm{~K}\right) \cdot\left(p_{s} /\left(p_{s}+q_{c}\right)\right)^{R / c_{p}}-273.15 \mathrm{~K}$,

where $T$ is the corrected air temperature, $T e_{N}$ is the temperature measured by the sensor in ${ }^{\circ} \mathrm{C}, p_{s}$ is the static pressure, $q_{c}$ is the dynamic pressure, $R$ is the specific gas constant of dry air, and $c_{p}$ is the specific heat capacity of dry air at constant pressure.

\subsection{Quality-processing of dropsonde measurements using ASPEN}

The need to apply quality-processing to the dropsondes' raw data of the campaign STABLE was shown by Tetzlaff (2016), who compared measurements of a dropsonde released over the MIZ with nearby airborne measurements obtained during an ascent and a descent. As stated by Tetzlaff (2016), the airborne measurements act as a useful reference for the dropsonde data due to the dropsonde's lower resolution and simpler instrumentation. The validation by Tetzlaff (2016) was performed over a region with 90-95\% sea ice cover on 20 March 2013, and due to on-ice flow conditions, a stable boundary layer had developed. The spatial difference between the aircraft profiles and the dropsonde was about $10 \mathrm{~km}$ near the release altitude and about $50 \mathrm{~km}$ near the surface. To focus only on sensor-related differences and to minimise effects by spatial inhomogeneities of the surface, Tetzlaff (2016) selected measurements between 800-2000 m height for the comparison.

Tetzlaff (2016) found a very good agreement between the airborne and dropsonde measurements for wind despite the spatial differences. The average temperature measured with the dropsonde was $0.38^{\circ} \mathrm{C}$ higher than during the aircraft profiles, which corresponded to twice the sensor's accuracy. The measured temperature variability was lower due to the lower sampling rate of the dropsonde's temperature sensor (Tetzlaff, 2016). Significant discrepancies occurred for relative humidity. The dropsonde data showed a dry bias of $7 \%$, which was close to the result of Vance et al. (2004) based on a comparison of the used dropsonde type with radiosonde and airborne data. In addition, the dropsonde's GPS sensor overestimated the altitude of the sonde by about $25 \mathrm{~m}$ (Tetzlaff, 2016). For the subsequent analysis of the dropsonde measurements in the MCAOs during STABLE, Tetzlaff (2016) and also Tetzlaff et al. (2014) thus used the pressure- and temperature-based geopotential height instead of the less reliable GPS height. They also removed data between the dropsonde release and the points where the sensors adapted to the ambient conditions in the atmosphere. A correction of the dry bias for humidity was not considered by them.

To provide a reliable, quality-controlled dropsonde data set, we applied most of the standard quality-processing mechanisms implemented in ASPEN (see Martin and Suhr, 2021) for correcting the raw data from the AVAPS. Most of following procedures have also been applied in other studies, for example, by Vömel et al. (2021) for their dropsonde data set. The individual steps are as follows:

- Correction of the temperature-dependent dry bias for relative humidity using an algorithm provided by Vaisala (see also Vömel et al., 2016)

- Ambient equilibration for pressure, temperature, and relative humidity: All data between the release of the sondes and the time after the individual sensors had adapted to the environmental atmospheric conditions (equilibration) were skipped 
by this correction. The range of the corresponding data being discarded was calculated by specifying the equilibration time as seven times the individual sensors' time constants. Pressure and temperature equilibration times were set equal. For humidity, the largest equilibration time was applied since the humidity sensor's time constant is largest. By this correction, most of the data between the first 200-300 $\mathrm{m}$ from the launch point were discarded.

- Ambient equilibration for wind, where $10 \mathrm{~s}$ was set as equilibration time

- Post-splash check: The three dropsondes released over the MIZ (see Table 2 and Sect. 2) had still transmitted data after they had already reached the surface, which was detected by ASPEN automatically. The respective last relevant data points were then specified manually. All the other dropsondes released over open water did not contain post-splash data.

- Satellite check: A minimum of six satellites was set as a lower limit to ensure reliable GPS-based data (position, GPS height, fall velocity, and wind).

- Wind error check: Wind measurements for which the corresponding error was higher than a certain threshold value were discarded. The threshold values specified in ASPEN are $1.5 \mathrm{~ms}^{-1}$ for measurements between $100 \mathrm{~m}$ and $10 \mathrm{~km}$ altitude and $1 \mathrm{~ms}^{-1}$ for measurements below $100 \mathrm{~m}$ and above $10 \mathrm{~km}$

- Removal of data points outside predefined limits, removal of outliers, and removal of wild points

- Dynamic correction for wind and temperature: This procedure helped to diminish errors caused by the temperature sensor's time lag and by the sonde's inertia that affected the wind determination.

- Calculation of surface pressure and temperature by extrapolation using the lowermost data point and the sonde's fall rate

- Calculation of the geopotential height based on pressure, temperature, and relative humidity: ASPEN uses upward integration starting from the surface, or downward integration starting from the release altitude if the dropsonde had not transmitted data until reaching the surface. For our dropsonde data, all dropsondes transmitted data to the surface (see Sect. 4 for more details).

- Vertical (fall) velocity check: The reliability of the dropsonde's horizontal wind measurements can be well linked to its fall velocity measured by GPS. ASPEN compares the GPS-based fall velocity to the hydrostatically derived fall velocity and the theoretical fall velocity, which are calculated based on the time-differentiated hydrostatic equation or based on the sonde's and parachute's aerodynamic properties using a model, respectively. If the GPS-based fall velocity differed too much from the other two velocities, the corresponding wind measurements were discarded.

- Calculation of the vertical wind component: This quantity was calculated based on the parachute's area and the parachute drag coefficient. We specified those as $0.09 \mathrm{~m}^{2}$ and 0.61 , respectively, following Wang et al. (2009).

More detailed explanations of these quality-processing mechanisms are given by Martin and Suhr (2021). 


\section{Data quality and statistics}

In this section, we focus on some of the effects by the applied quality-processing mechanisms on the airborne and dropsonde measurements, and we mention the reasons for unreliable or missing data that occurred for a very small number of the sondes. We also provide an overview of the wind speed error distribution for the individual dropsonde measurements and on the horizontal distances covered by both aircraft and the dropsondes.

\subsection{Airborne measurements}

Subsequently, we briefly compare uncorrected and corrected airborne temperature data as well as the aircraft's altitude measured by GPS and as derived from the recorded static pressure. According to Eq. (1), temperatures are generally lower after the correction. For the data set described here, the average difference between uncorrected and corrected temperatures is between $2-3 \mathrm{~K}$ for all flight legs. The maximum difference among all flight legs is almost $5 \mathrm{~K}$.

A distribution of the differences between the aircraft's height measured by GPS to the corrected pressure altitude is shown in Fig. 2. Mostly, the two data series differ by less than $10 \mathrm{~m}$. Larger deviations are shown especially for some profiles of 4 March, peaking at a difference of more than $30 \mathrm{~m}$ on average for the profile T6. For most profiles, the values measured by GPS were higher than the pressure-based values, which holds also for the height measurements of the dropsondes (see Sect. 3.2 and also Sect. 4.2.1).

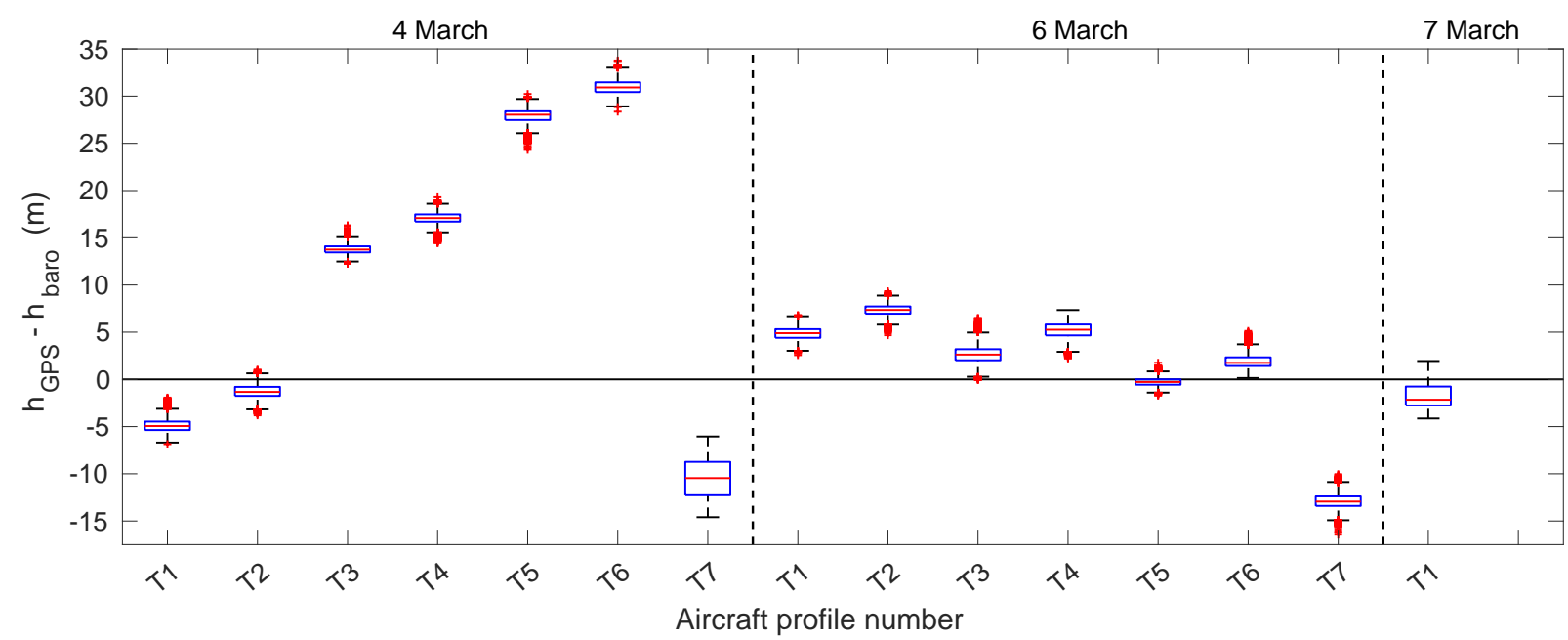

Figure 2. Distribution of the differences between the aircraft's height measured by GPS $\left(h_{G P S}\right)$ to the corrected pressure altitude $\left(h_{b a r o}\right)$ for each aircraft profile (see Table 1). Red lines show the median, the boxes are bounded by the upper and lower quartiles, the whiskers include the interval of approximately $99.7 \%$ of the values, and red crosses denote outliers. 
https://doi.org/10.5194/essd-2021-341

Preprint. Discussion started: 3 November 2021

(c) Author(s) 2021. CC BY 4.0 License.

(c) (i)

\subsection{Dropsonde measurements}

The removal of data points that did not pass the quality-processing procedures by ASPEN explained in Sect. 3 predominantly concerned the uppermost dropsonde measurements and thus regions where the sensors had not yet adapted to the ambient conditions after the sondes' releases. In addition, a small number of data namely just $2-5 \mathrm{~s}$ measurement time of all sondes was removed by the vertical fall velocity check described in Sect. 3. A removal of wind measurements with wind error values exceeding the limits mentioned in Sect. 3 also mostly concerned the measurements just below the aircraft.

Some of the uppermost GPS-derived data of the sondes D5 from 4 March, D1 from 6 March, and D8 from 26 March were removed since the minimum number of satellites required for the calculations had not been reached. For the latter two sondes, this means that GPS-derived data are not available for the uppermost $40-50 \mathrm{~m}$ after the pressure and temperature sensors had already adapted to the ambient conditions. For the sonde D5 from 4 March, GPS-derived data from the uppermost $200 \mathrm{~m}$ are missing in the quality-controlled data since the reported number of GPS satellites was zero at that time. In almost all dropsonde data series, a very small number of non-consecutive data points (mostly less than 10 per sonde) was removed by ASPEN since they were marked as having a cyclic redundancy check error, either for the pressure-temperature unit or for the GPS module. The dynamical adjustment applied to the temperature and wind measurements is the only procedure that actually modifies the measured data (Martin and Suhr, 2021). Regarding the temperature data, the adjustment leads to a seemingly faster response of the dropsondes' temperature sensors to strong small-scale changes with height. This helps to overcome the smaller temperature variability captured by the sondes as compared to the aircraft measurements (see also Tetzlaff, 2016). We illustrate this effect in Fig. 3 for the three dropsondes that were released over sea ice. It is shown that the dynamical adjustment leads to more pronounced upper and lower boundaries of the temperature inversions, especially for those at a height of about 200-400 m, whereas the remaining measured temperature data are barely affected. For all dropsonde measurements, the average temperature of each profile changed by only about $0.05-0.25 \mathrm{~K}$ by the dynamical adjustment. The dynamical adjustment for wind caused hardly any change of the original wind values (not shown).

\subsubsection{Geopotential height calculation}

Since the three dropsondes that terminated over sea ice contained post-splash data, we can be sure that they transmitted data down to the surface. From the corresponding data series, we found that the GPS-based height was at about $25-35 \mathrm{~m}$ at the point where the surface was reached, which is similar to the finding by Tetzlaff (2016) mentioned in Sect. 3. The other sondes transmitted data down to a GPS-derived height of about 25-50 m without containing post-splash data. Hence, we can assume that all sondes successfully transmitted data until reaching the sea surface. The subsequent upward integration of the geopotential height was performed by ASPEN based on extrapolated surface data since the lowermost measurements transmitted by the sondes were located slightly above the surface. This is because the measurements were typically transmitted at the end of the $0.5 \mathrm{~s}$ measurement cycle causing a loss of data for the lowermost few metres if no post-splash data was reported (Hock and Franklin, 1999). The upward integration was performed until the uppermost quality-processed pressure value was reached. 


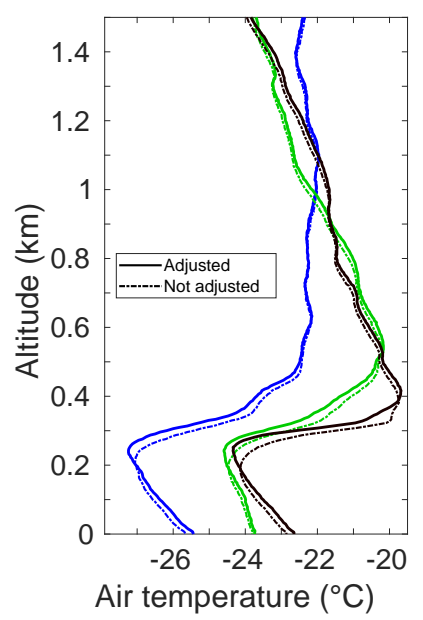

Figure 3. Air temperature data of the dropsondes D1 from 4 March (blue) and D1 (green) and D2 (dark red) from 26 March (see Table 2) with and without the dynamical adjustment of ASPEN (see Martin and Suhr, 2021). Only the lowest $1.5 \mathrm{~km}$ of the profiles are shown.

Mostly, this is lower than the first few GPS-derived values of the wind by differences in the equilibration times assumed (Sect. 3.2). Thus, no geopotential altitude could be obtained for the uppermost few quality-processed wind data.

\subsubsection{Wind speed error}

In the dropsondes' raw data, every data point of the horizontal wind is supplemented by a value for its error, which is determined based on the measurement uncertainties in the sondes' horizontal and vertical velocities and accelerations (Hock and Franklin, 1999). As explained in Sect. 3, wind measurements exceeding a certain error threshold are discarded by ASPEN. In Fig. 4, we show the distribution of the wind error for the remaining quality-processed wind data. It is shown that in most cases the median as well as the lower and upper quartiles of the wind error are between 0.4 and $0.7 \mathrm{~ms}^{-1}$. Moreover, the whiskers in Fig. 4 denote that for all sondes approximately $99.7 \%$ of the wind error values are between 0.4 and $0.9 \mathrm{~ms}^{-1}$. However, for some data points, the wind error amounts to almost $1.5 \mathrm{~ms}^{-1}$.

\subsection{Horizontal distance}

For model validation, the dropsondes' drift distances and the flight distances during the aircraft's descents/ascents might be important so that we provide this information in Fig. 5. Since we decided to plot the distances against the pressure-based altitude and not against the one based on GPS, the dropsondes' drift distances (Fig. 5a-d) are not shown for the layer where the meteorological sensors had adapted to the environmental atmospheric conditions after release (see also Sect. 3.2). We also added the release altitudes of all sondes in Fig. $5 \mathrm{a}-\mathrm{d}$, where this information is only available from GPS. Most of the sondes showed a monotonic drift mainly along the main flow direction in the respective MCAO, except for D2 from 6 March. Especially on 26 March, some sondes drifted faster in the lowest kilometre of the atmosphere than further above, presumably 


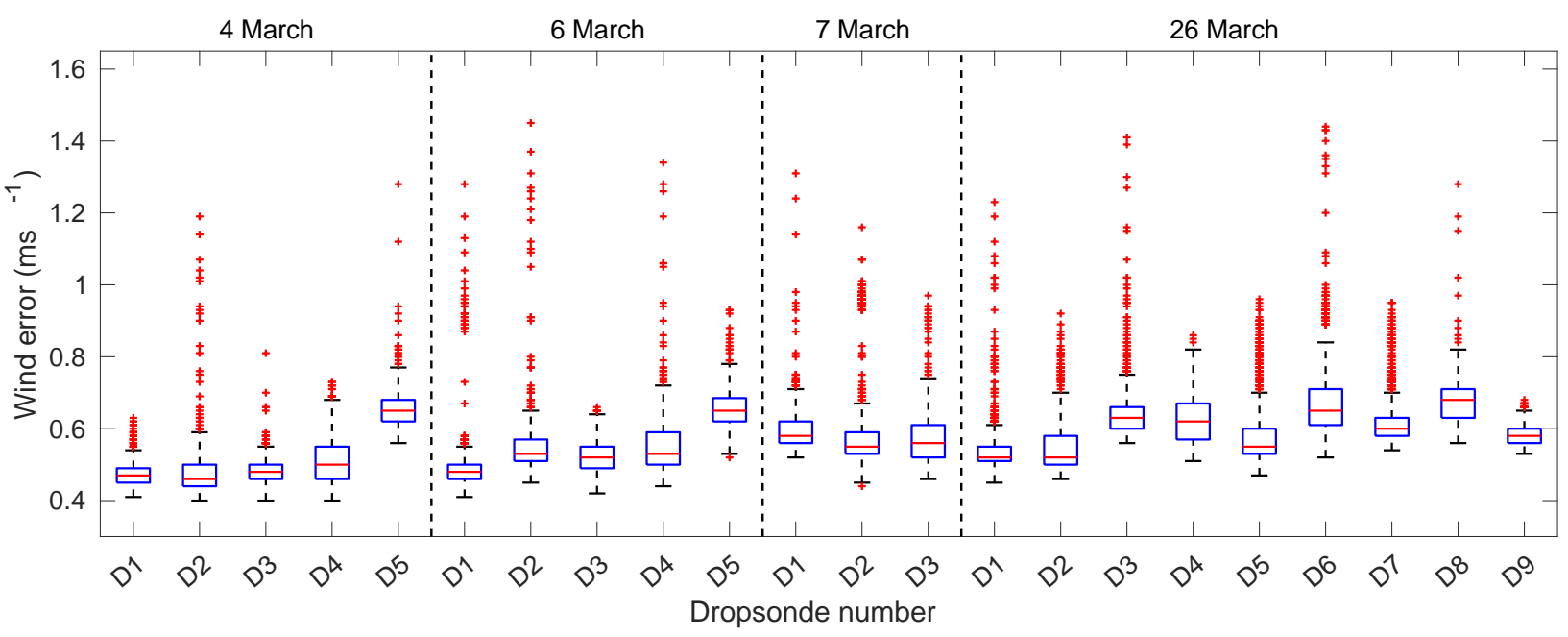

Figure 4. Distribution of the wind errors for each dropsonde listed in Table 2. Red lines show the median, the boxes are bounded by the upper and lower quartiles, the whiskers include the interval of approximately $99.7 \%$ of the values, and red crosses denote outliers.

by stronger winds in the convective ABL compared to the free atmosphere. None of the sondes had been drifting more than $5 \mathrm{~km}$, where the drift was much stronger on 4 March than on the other days.

Regarding the aircraft profiles discussed here, during most of them, the aircraft had a pitch angle of not more than about $\pm 2- \pm 10^{\circ}$. Due to the small inclination, the travel distance during one descent/ascent is much larger than for dropsondes and horizontal distances summed up to $30-40 \mathrm{~km}$ for an ascent from the surface to $3 \mathrm{~km}$ altitude (Fig. $5 \mathrm{e}-\mathrm{g}$ ). During the shorter profiles over the MIZ further north, the horizontal travel distance was mostly in the range $2-13 \mathrm{~km}$.

\section{Cold-air outbreaks}

In this section, we focus on the meteorological characteristics of the MCAOs based on the quality-processed airborne and dropsonde data. Figures 6 and 7 show vertical cross-sections of temperature, wind speed, as well as specific and relative humidity. Note that for the latter quantity, we show only those regions where saturation over ice was reached indicating where clouds had presumably been present. Panels of the total values of relative humidity are shown in Appendix B. All cross-sections are designed in a similar way as shown in Tetzlaff et al. (2014) for potential temperature and in Tetzlaff (2016) for all four variables. Data from the aircraft's profiles are the same in their and in our illustrations, whereas different corrections were applied by them to the dropsonde data (see Sect. 3.2). Figures 6 and 7 show also the ABL height on each day, which was also adapted from Tetzlaff (2016). We provide only a brief description of the cross-sections and refer to Tetzlaff et al. (2014) and Tetzlaff (2016) for a more detailed interpretation. 
(a)

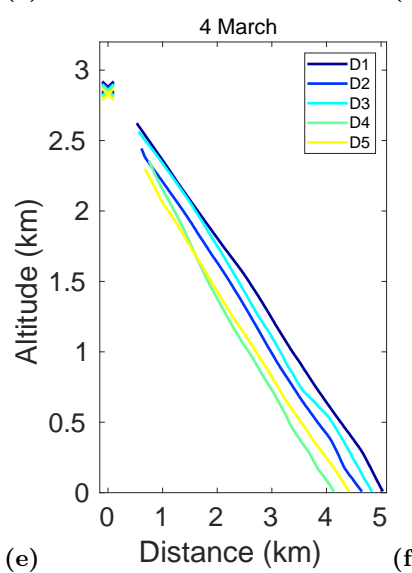

(e)

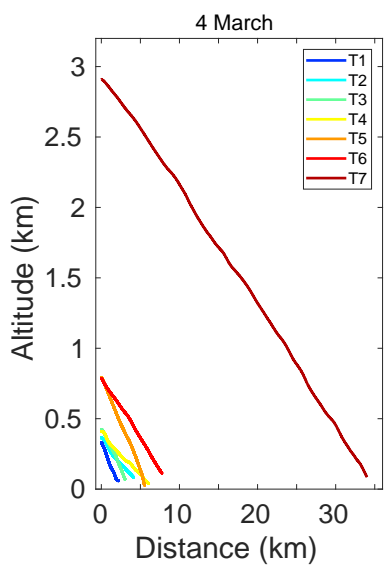

(b)

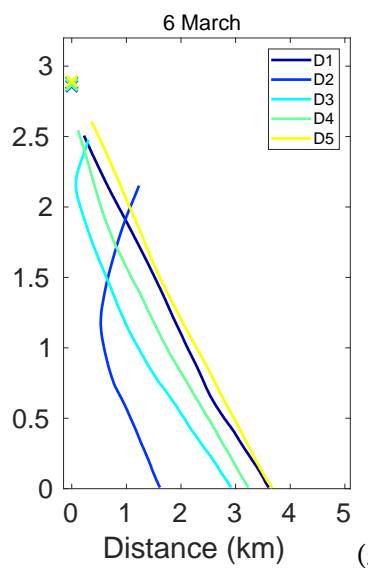

(c)

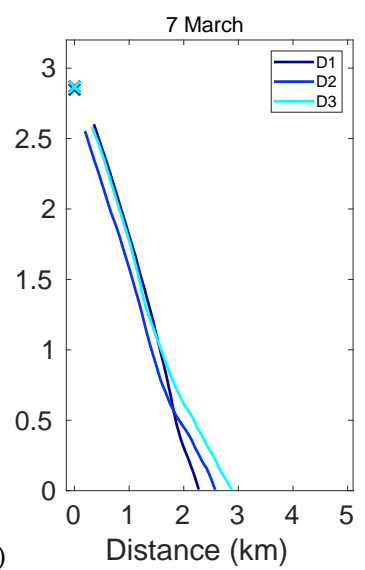

(d)

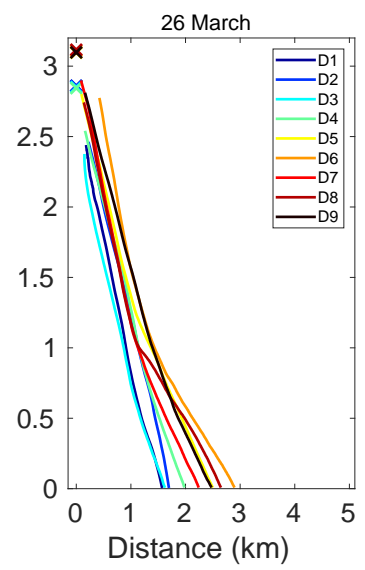

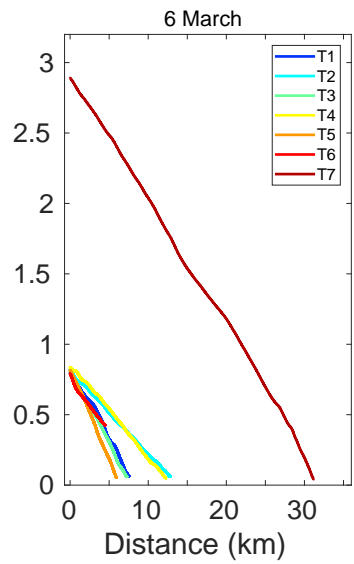

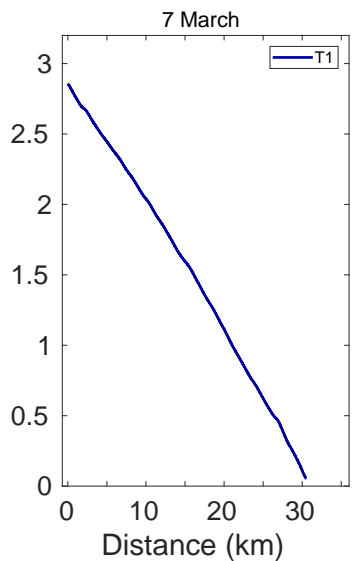

Figure 5. Horizontal drift distances of the dropsondes (a)-(d) and distances flown by the aircraft during ascents and descents (e)-(g). Distances are calculated with respect to the uppermost measurement point. For the dropsondes, this information is missing for the uppermost layer (see text) and coloured crosses refer to the dropsondes' release altitudes derived via GPS.

\subsection{MCAO episode from 4 to 7 March}

On 4 March, the observed MCAO was characterised by a shallow, slightly stably stratified ABL of about $250 \mathrm{~m}$ depth over sea ice and by a strong increase in both ABL height and temperature with increasing distance over open water (Fig. 6a). As noted by Tetzlaff et al. (2014), the resulting ABL height of about $2500 \mathrm{~m}$ at a distance of $220 \mathrm{~km}$ was extraordinarily high as compared to MCAOs observed in the early 1990's (e.g., Brümmer, 1997). A strong increase with increasing distance was also observed for both specific humidity and horizontal wind speed inside the ABL (Fig. 6c, e). The relative humidity distribution depicts clouds in the entire ABL over open water with increasing cloud base and top further to the south (Fig. 6g). Another shallow cloud layer is denoted above the ABL at about $50 \mathrm{~km}$ distance. Moreover, it is shown that clouds were presumably also present over sea ice on that day, except for the northernmost flight leg. This agrees with visual observations made by the 
https://doi.org/10.5194/essd-2021-341

Preprint. Discussion started: 3 November 2021

(c) Author(s) 2021. CC BY 4.0 License.

(c) (i)

participants of the corresponding research flight.

On 6 March, the ABL over sea ice was slightly shallower than two days before and the increase in both temperature and ABL

height with increasing distance was not as pronounced as on 4 March (Fig. 6b). The specific humidity distribution denotes a slightly more humid ABL over sea ice but a similarly humid ABL over open water as compared to 4 March (Fig. 6d). Horizontal winds had basically decreased from 4 to 6 March, especially over open water (Fig. 6f). The relative humidity distribution denotes the presence of clouds over both sea ice and the open ocean. Compared to 4 March, less clouds might have been present over sea ice on 6 March (Fig. 6h).

Unlike for the previous two days, no airborne measurements are available for the MIZ region on 7 March. The corresponding cross-sections indicate a weakening of the MCAO as compared to 4 and 6 March. Namely, specific humidity and horizontal wind speed in the ABL over open water were lower than on 4 and 6 March and also the increase of temperature and ABL height with increasing distance were less pronounced (Fig. 7a, c, e). The corresponding relative humidity distribution (Fig. 7g) denotes several clouds not only in but also above the ABL along the entire cross-section.

\subsection{MCAO event on 26 March}

The measurements of the dropsondes D2-D5, which were released almost exactly along the main ABL flow direction in the MCAO, denote a deepening of the ABL from approximately $250 \mathrm{~m}$ near $-50 \mathrm{~km}$ distance over the MIZ to $1250 \mathrm{~m}$ height at about $160 \mathrm{~km}$ distance over open water (Fig. 7b). This coincides with a potential temperature increase in the ABL from approximately $248 \mathrm{~K}$ to $258 \mathrm{~K}$, and a slight increase in both specific humidity and horizontal wind speed (Fig. 7b, d, f). Figure 7h denotes that clouds were presumably present in the entire ABL along the MCAO orientation and also above the ABL over the polynya region. In the region further downwind where the dropsondes D6-D9 were released, the ABL-averaged wind direction had turned slightly to north (see Fig. 1d), and the ABL had not deepened further with increasing fetch.

\section{Data availability}

The data are available on PANGAEA repository (Lüpkes et al., 2021a). All 37 data series can be found at https://doi.pangaea. de/10.1594/PANGAEA.936635 together with a brief data description. The individual DOIs of each data series are also listed in this paper in Tables 1 and 2. All data series are provided as tab-delimited text files (ascii). Missing or discarded measurements are indicated by empty fields in those files, where this only concerns the dropsonde data. All data are supplemented by metadata with information on the location and time of the measurements, the corresponding event, and on the measured quantities.

\section{Conclusions}

315 The investigation of atmospheric convection and boundary layer modifications associated with marine cold-air outbreaks (MCAOs) were one of the main objectives of the aircraft campaign STABLE in March 2013. MCAOs occurring over the Fram Strait region were observed on four days using highly resolved atmospheric measurements from instruments mounted 
(a)
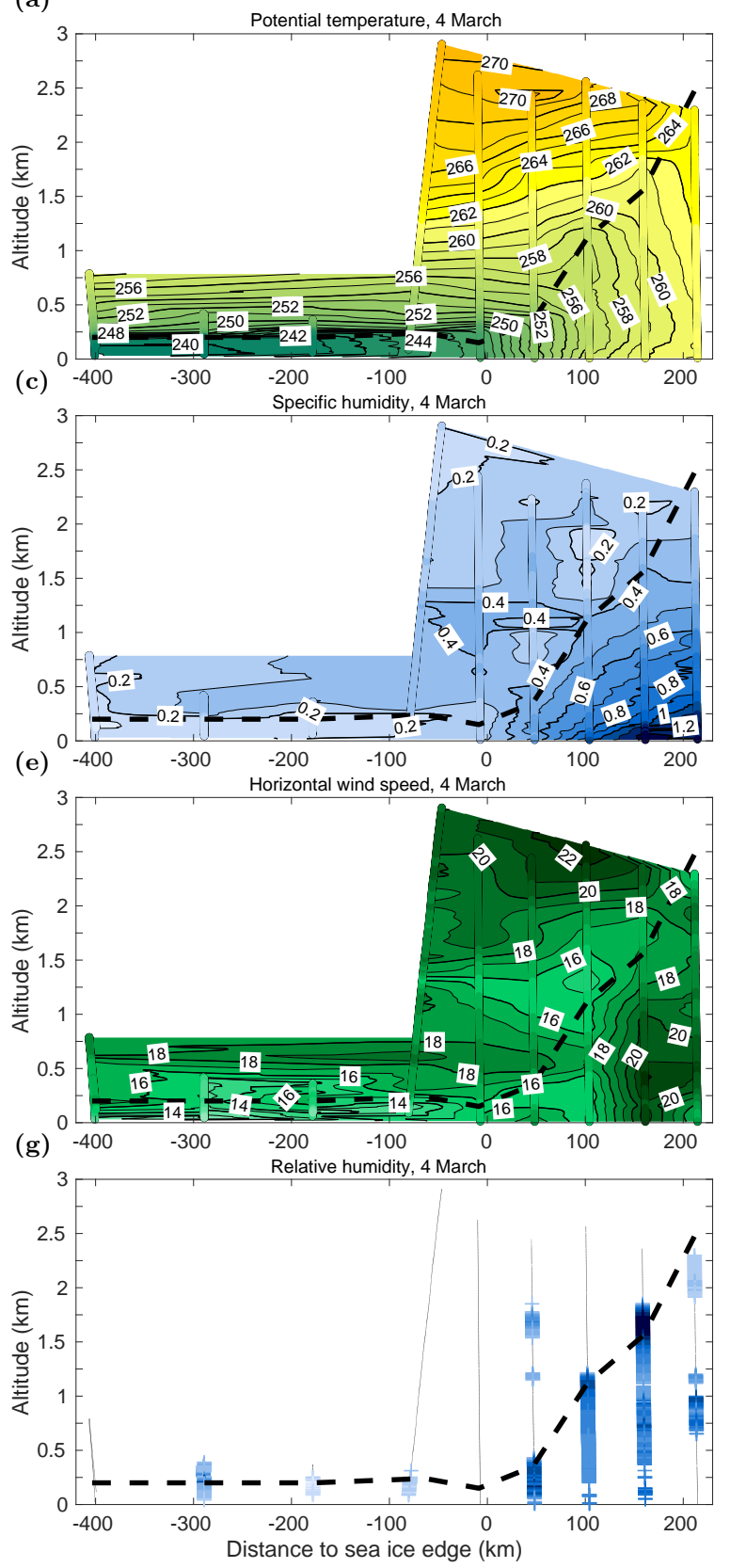

(b)

(d)

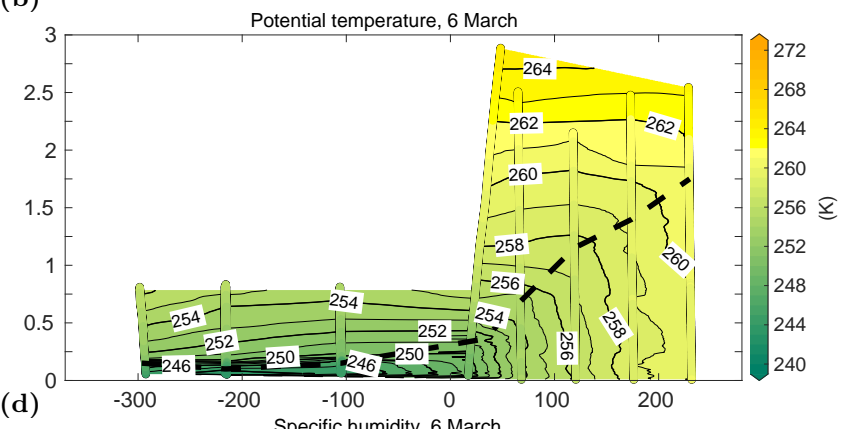

(f)
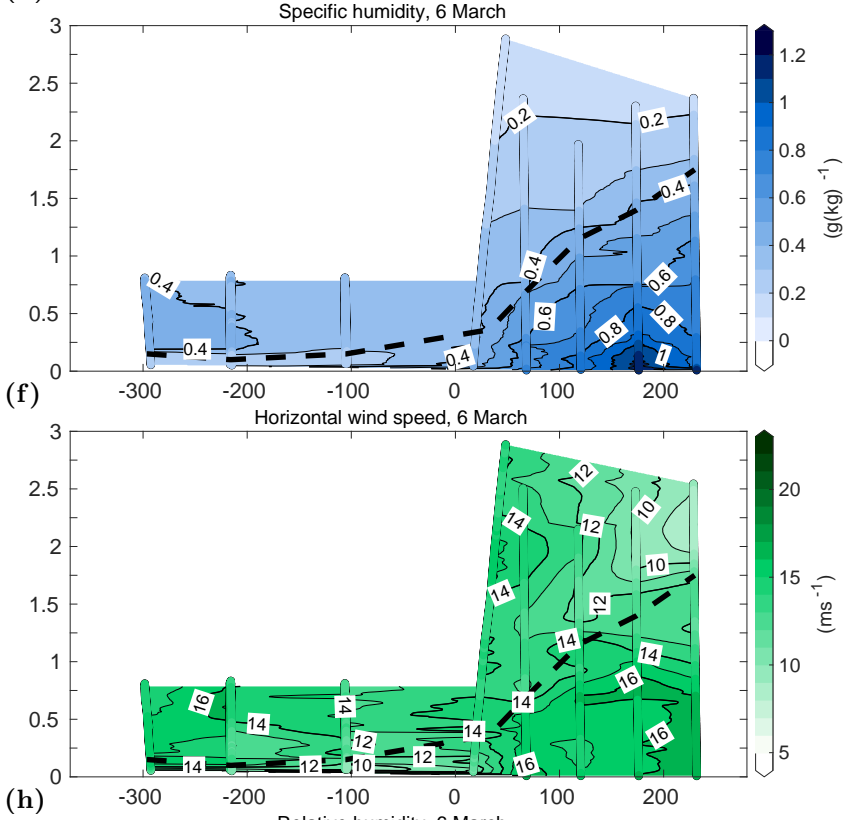

(h)

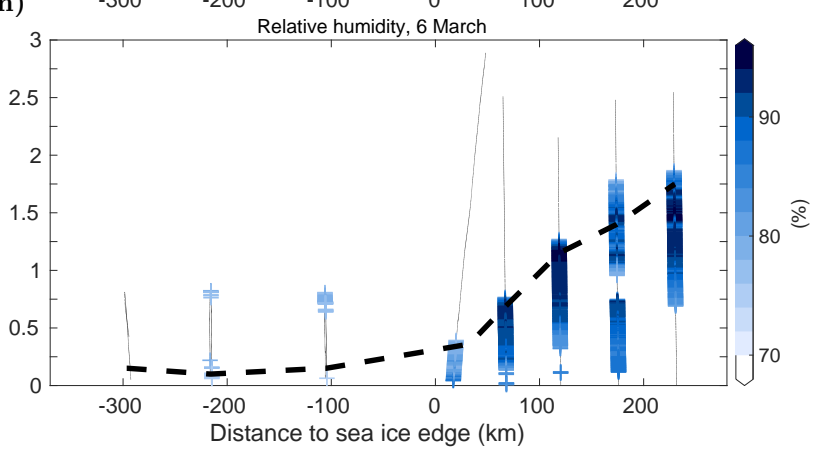

Figure 6. Vertical cross-sections of (a)-(b) potential temperature, (c)-(d) specific humidity, (e)-(f) horizontal wind speed, and (g)-(h) relative humidity in saturated areas with respect to an ice surface for (a), (c), (e), (g) 4 March and (b), (d), (f), (h) 6 March 2013 based on airborne and dropsonde measurements. Dashed black lines denote the ABL height. Modified based on Tetzlaff et al. (2014) and Tetzlaff (2016). 
(a)
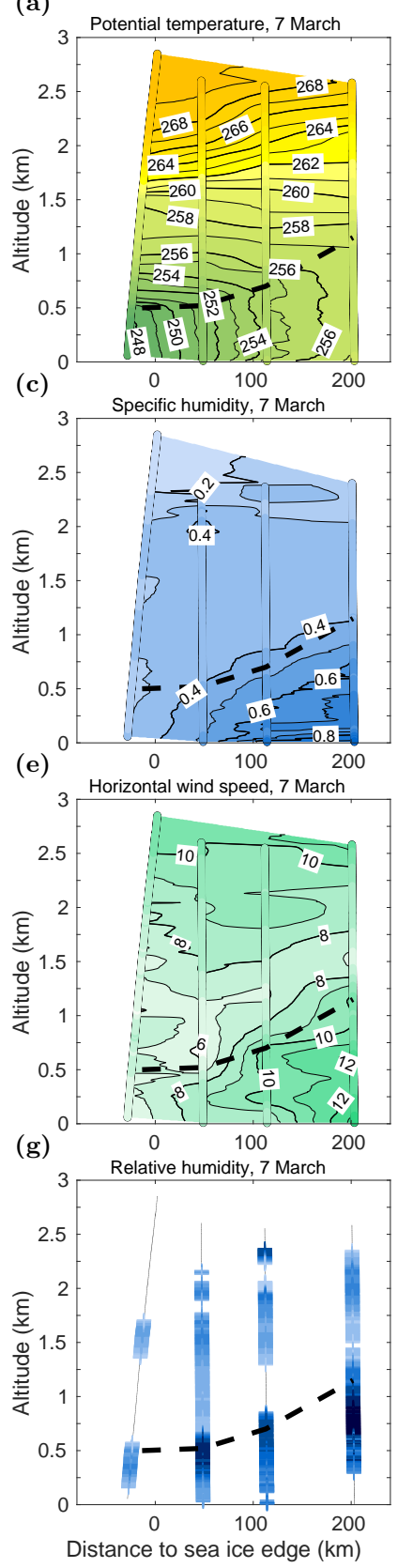

(b)
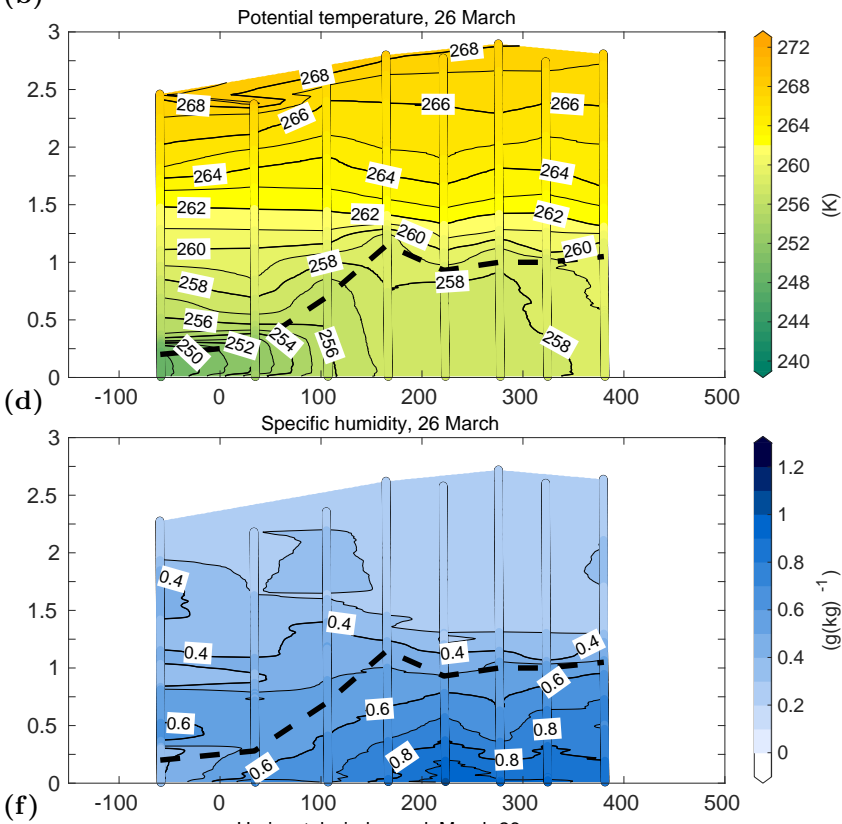

(f)
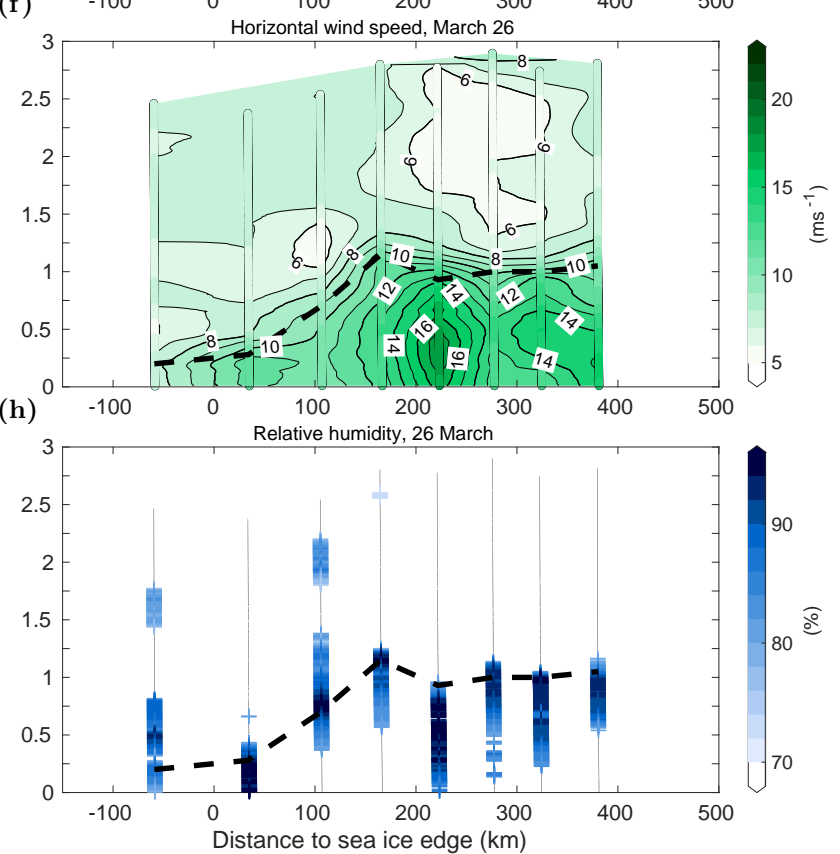

Figure 7. Same as Fig. 6, but (a), (c), (e), (g) show vertical cross-sections for 7 March and (b), (d), (f), (h) for 26 March 2013. Modified based on Tetzlaff et al. (2014) and Tetzlaff (2016).

in and at the aircraft's nose-boom and by dropsondes. The observations took place in a period of an unusually large Whaler's Bay Polynya north of Svalbard (see Tetzlaff et al., 2014; Tetzlaff, 2016). We gave a detailed description of the corresponding 

to observations over the marginal sea ice zone up to about $400 \mathrm{~km}$ upwind of the ice edge, whereas most of the dropsonde measurements took place over the open ocean. Hence, the research flights during STABLE were arranged to allow detailed observations of the vertical structure of the lower troposphere mainly along the mean wind direction in the boundary layer during the MCAOs.

To obtain a high-quality data set, we applied several quality-processing steps for both aircraft and dropsonde measurements. Especially for the dropsonde data, multiple corrections had to be applied for which we used quality-processing mechanisms implemented in the Atmospheric Sounding Processing Environment software (ASPEN, Martin and Suhr, 2021). This not only helped to remove suspicious data points but also to, for example, correct the dry bias found in the measurements of relative humidity with the used dropsonde type (see Vance et al., 2004). Moreover, a dynamical adjustment applied to the dropsondes' temperature measurements improved the representation of the observed temperature inversions and generally helped to overcome the reduction in the captured temperature variability as compared to the aircraft measurements.

Altogether, the data set we presented here consists of reliable and highly resolved atmospheric measurements of temperature, humidity, wind, and pressure. It provides a detailed representation of the vertical structure of the lower troposphere inside and above the evolving boundary layers during the MCAOs. Thus, it might serve as a valuable reference for validation of model simulation results for such events of polar airmass transformations.

\section{Appendix A: Flight tracks}

Figure A1 illustrates the flight tracks of the research flights from STABLE on 4, 6, 7, and 26 March 2013. On 4 and 6 March, the flight patterns mainly consisted of meridionally oriented flight legs in the region of the MCAOs (see also Sect. 2.1). On 7 March, additional measurements were performed during a low-level flight leg nearly parallel to the ice margin west of Svalbard. On 26 March, airborne measurements were performed over a lead located near $81.6^{\circ} \mathrm{N}$ and $21.4^{\circ} \mathrm{E}$ (see also Tetzlaff et al., 2015; Michaelis et al., 2021) prior to the measurements in the MCAO that occurred over the Whaler's Bay Polynya.

\section{Appendix B: Vertical cross-sections of relative humidity}

Similar to Fig. 6g, h and Fig. 7g, h shown in Sect. 5, we provide in Fig. B1-B2 vertical cross-sections of the relative humidity based on the airborne and dropsonde measurements for 4, 6, 7, and 26 March 2013 in the respective MCAOs. Unlike the corresponding panels in Sect. 5, here we show the distribution of the total relative humidity. While Fig. 6g, h and Fig. 7g, h helped to detect regions of saturated air and thus clouds, Fig. B1 and Fig. B2 help to better identify dry and humid regions in the atmosphere nearly along the main MCAO orientations. For example, it is clearly shown that on 4 March, the region of the free atmosphere above the convective ABL over open water was basically much drier than on 6 March (Fig. B1a, b). Low relative humidity is also shown above the temperature inversion on 26 March, starting at a fetch of about $150 \mathrm{~km}$ (Fig. B1c). 
https://doi.org/10.5194/essd-2021-341

Preprint. Discussion started: 3 November 2021

(c) Author(s) 2021. CC BY 4.0 License.

(c) (1)

(a)

(c)
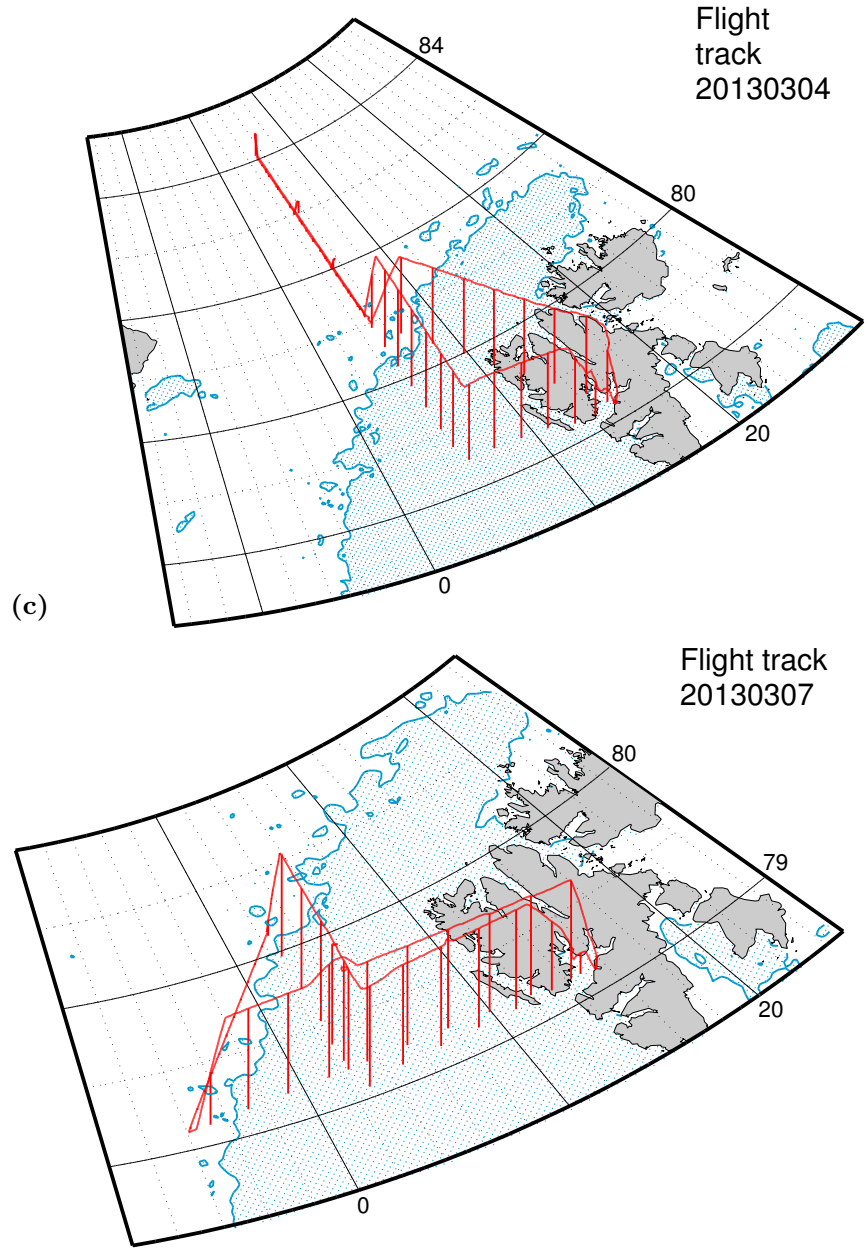

(b)

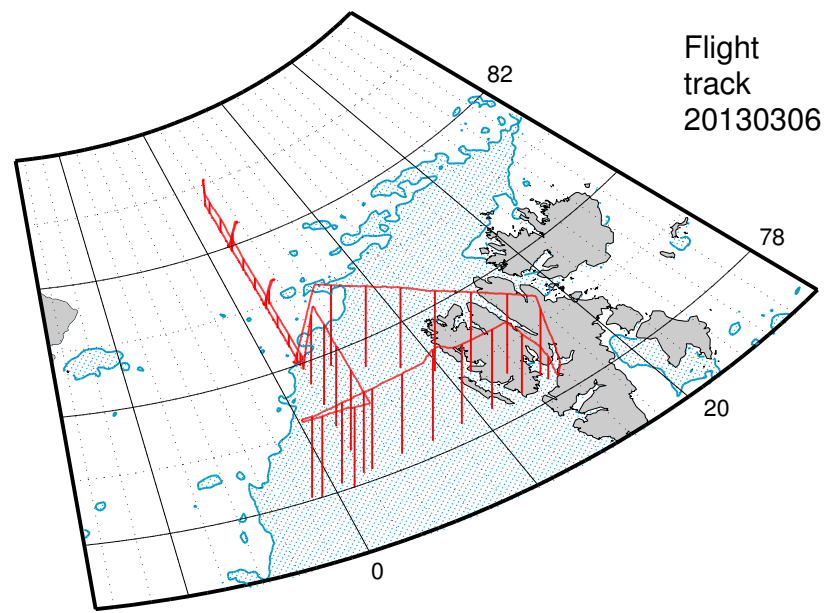

(d)

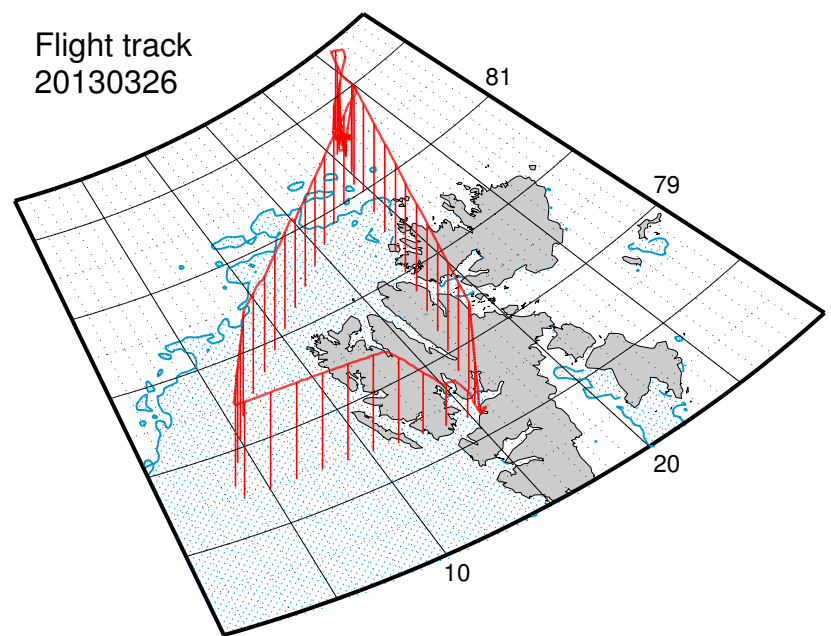

Figure A1. 3D illustration of the flight tracks on 4 March (a), 6 March (b), 7 March (c), and 26 March 2013 (d) plotted over the ice edge based on a $70 \%$ threshold value of the ice concentration (see also Fig. 1 in Sect. 2).

Author contributions. AS, CL, JH, GB, and TV all participated in planning the research flights during STABLE, and they operated the instruments onboard the aircraft including the AVAPS dropsonde system. Quality-processing of the data was performed by JH for the airborne data and by JM for the dropsonde data using the dropsonde software ASPEN. JM performed the data analyses and prepared the manuscript. All co-authors contributed to the final writing of the paper.

Competing interests. The authors declare that they have no conflict of interest. 
(a)

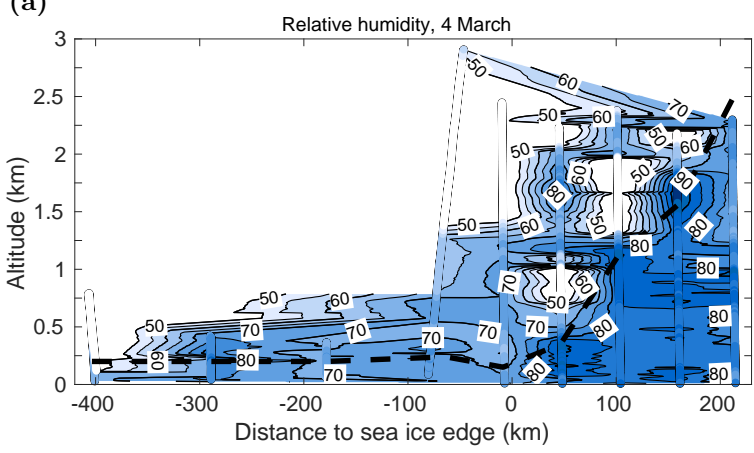

(b)

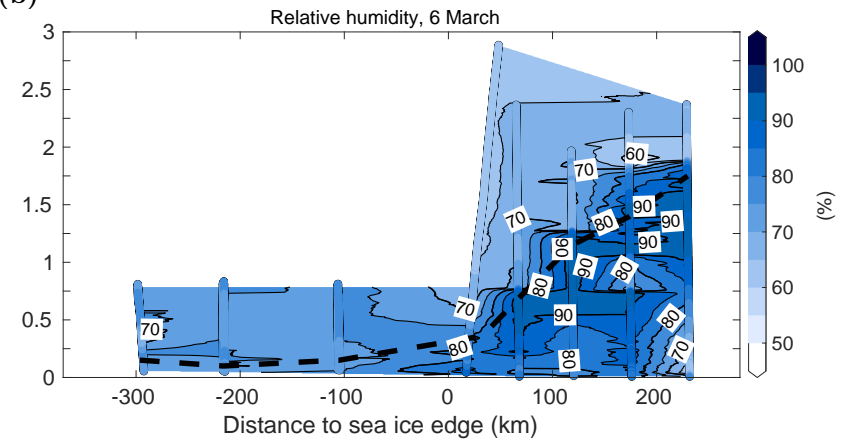

Figure B1. Same as Fig. 6 but vertical cross-sections are shown for the total values of relative humidity on (a) 4 March and (b) 6 March 2013. Modified based on Tetzlaff et al. (2014) and Tetzlaff (2016).
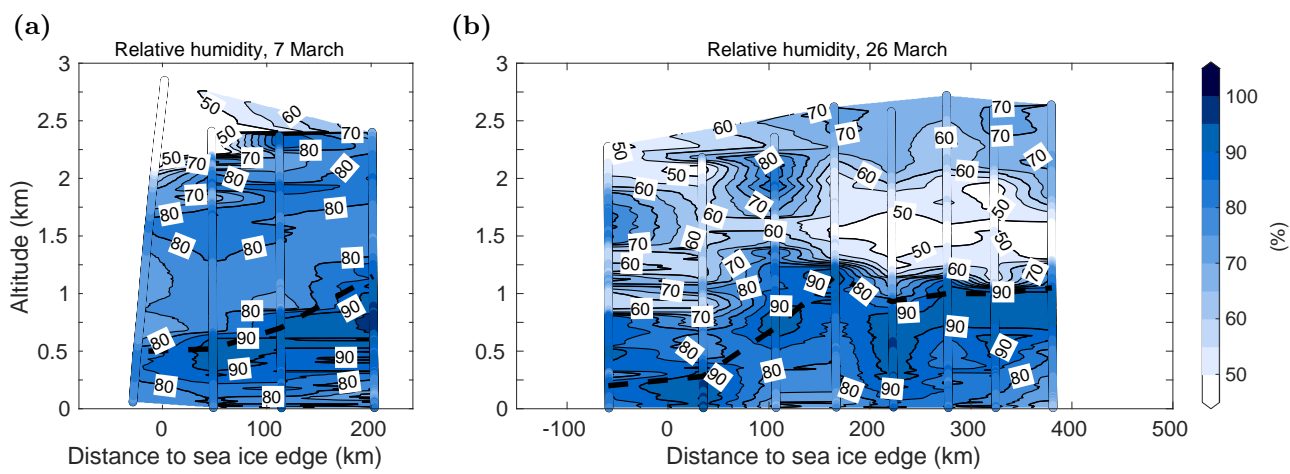

Figure B2. Same as Fig. 7 but vertical cross-sections are shown for the total values of relative humidity on (a) 7 March and (b) 26 March 2013. Modified based on Tetzlaff et al. (2014) and Tetzlaff (2016).

Acknowledgements. We gratefully acknowledge the funding by the Deutsche Forschungsgemeinschaft (DFG, German Research Foundation), project no. 268020496 - TRR 172, within the Transregional Collaborative Research Center: "ArctiC Amplification: Climate Relevant Atmospheric and SurfaCe Processes, and Feedback Mechanisms (AC) ${ }^{3}$ ". We are grateful to all aircraft engineers and the flight crew for their support during the campaign. We also thank Andreas Walbröl and Jan Chylik for helpful comments. 
https://doi.org/10.5194/essd-2021-341

Preprint. Discussion started: 3 November 2021

(c) Author(s) 2021. CC BY 4.0 License.

(c) (i)

\section{References}

Brümmer, B.: Boundary-layer modification in wintertime cold-air outbreaks from the Arctic sea ice, Bound-lay. Meteorol., 80, 109-125, https://doi.org/10.1007/BF00119014, 1996.

Brümmer, B.: Boundary layer mass, water, and heat budgets in wintertime cold-air outbreaks from the Arctic sea ice, Mon. Weather Rev., 125, 1824-1837, https://doi.org/10.1175/1520-0493(1997)125<1824:BLMWAH>2.0.CO;2, 1997.

Brümmer, B.: Roll and cell convection in wintertime Arctic cold-air outbreaks, J. Atmos. Sci., 56, 2613-2636, https://doi.org/10.1175/15200469(1999)056<2613:RACCIW>2.0.CO;2, 1999.

Brümmer, B. and Pohlmann, S.: Wintertime roll and cell convection over Greenland and Barents Sea regions: A climatology, J. Geophys. Res.-Atmos., 105, 15 559-15 566, https://doi.org/10.1029/1999JD900841, 2000.

Brümmer, B., Rump, B., and Kruspe, G.: A cold air outbreak near Spitsbergen in springtime—Boundary-layer modification and cloud development, Bound-lay. Meteorol., 61, 13-46, https://doi.org/10.1007/BF02033993, 1992.

Cavalieri, D. J. and Parkinson, C. L.: Arctic sea ice variability and trends, 1979-2010, The Cryosphere, 6, 881-889, https://doi.org/10.5194/tc6-881-2012, 2012.

Chechin, D. G. and Lüpkes, C.: Boundary-layer development and low-level baroclinicity during high-latitude cold-air outbreaks: A simple model, Bound-lay. Meteorol., 162, 91-116, https://doi.org/10.1007/s10546-016-0193-2, 2017.

Chechin, D. G., Lüpkes, C., Repina, I. A., and Gryanik, V. M.: Idealized dry quasi 2-D mesoscale simulations of cold-air outbreaks over the marginal sea ice zone with fine and coarse resolution, J. Geophys. Res.-Atmos., 118, 8787-8813, https://doi.org/10.1002/jgrd.50679, 2013.

Draxler, R. R. and Rolph, G. D.: HYSPLIT (HYbrid Single-Particle Lagrangian Integrated Trajectory) model access via NOAA ARL READY website (http://ready.arl.noaa.gov/HYSPLIT.php), NOAA Air Resources Laboratory, Silver Spring, MD, $25,2010$.

Ehrlich, A., Wendisch, M., Lüpkes, C., Buschmann, M., Bozem, H., Chechin, D., Clemen, H.-C., Dupuy, R., Eppers, O., Hartmann, J., Herber, A., Jäkel, E., Järvinen, E., Jourdan, O., Kästner, U., Kliesch, L.-L., Köllner, F., Mech, M., Mertes, S., Neuber, R., RuizDonoso, E., Schnaiter, M., Schneider, J., Stapf, J., and Zanatta, M.: A comprehensive in situ and remote sensing data set from the Arctic CLoud Observations Using airborne measurements during polar Day (ACLOUD) campaign, Earth Syst. Sci. Data, 11, 1853-1881, https://doi.org/10.5194/essd-11-1853-2019, 2019.

Etling, D. and Brown, R. A.: Roll vortices in the planetary boundary layer: A review, Bound-lay. Meteorol., 65, 215-248, https://doi.org/10.1007/BF00705527, 1993.

Fletcher, J., Mason, S., and Jakob, C.: The climatology, meteorology, and boundary layer structure of marine cold air outbreaks in both hemispheres, J. Climate, 29, 1999-2014, https://doi.org/10.1175/JCLI-D-15-0268.1, 2016.

Gryanik, V. M. and Hartmann, J.: A turbulence closure for the convective boundary layer based on a two-scale mass-flux approach, J. Atmos. Sci., 59, 2729-2744, https://doi.org/10.1175/1520-0469(2002)059<2729:ATCFTC>2.0.CO;2, 2002.

Gryschka, M., Drüe, C., Etling, D., and Raasch, S.: On the influence of sea-ice inhomogeneities onto roll convection in cold-air outbreaks, Geophys. Res. Lett., 35, https://doi.org/10.1029/2008GL035845, 2008.

Gryschka, M., Fricke, J., and Raasch, S.: On the impact of forced roll convection on vertical turbulent transport in cold air outbreaks, J. Geophys. Res.-Atmos., 119, 12-513, https://doi.org/10.1002/2014JD022160, 2014.

Hartmann, J., Kottmeier, C., and Raasch, S.: Roll vortices and boundary-layer development during a cold air outbreak, Bound-lay. Meteorol., 84, 45-65, https://doi.org/10.1023/A:1000392931768, 1997. 
https://doi.org/10.5194/essd-2021-341

Preprint. Discussion started: 3 November 2021

(c) Author(s) 2021. CC BY 4.0 License.

(c) (i)

Hartmann, J., Gehrmann, M., Kohnert, K., Metzger, S., and Sachs, T.: New calibration procedures for airborne turbulence measurements and accuracy of the methane fluxes during the AirMeth campaigns, Atmos. Meas. Tech., 11, 4567-4581, https://doi.org/10.5194/amt-114567-2018, 2018.

Hock, T. F. and Franklin, J. L.: The NCAR GPS dropwindsonde, B. Am. Meteorol. Soc., 80, 407-420, https://doi.org/10.1175/15200477(1999)080<0407:TNGD>2.0.CO;2, 1999.

Ikonen, I., Demetriades, N. W. S., and Holle, R. L.: Vaisala dropsondes: History, status, and applications, in: 29th Conference on Hurricanes and Tropical Meteorology, Tucson, Arizona, 10-14 May 2010, https://ams.confex.com/ams/29Hurricanes/webprogram/Paper168031.html, 2010 .

Kolstad, E. W. and Bracegirdle, T. J.: Marine cold-air outbreaks in the future: An assessment of IPCC AR4 model results for the Northern Hemisphere, Clim. Dynam., 30, 871-885, https://doi.org/10.1007/s00382-007-0331-0, 2008.

Landgren, O. A., Seierstad, I. A., and Iversen, T.: Projected future changes in Marine Cold-Air Outbreaks associated with Polar Lows in the Northern North-Atlantic Ocean, Clim. Dynam., 53, 2573-2585, https://doi.org/10.1007/s00382-019-04642-2, 2019.

Liu, A. Q., Moore, G. W. K., Tsuboki, K., and Renfrew, I. A.: The effect of the sea-ice zone on the development of boundary-layer roll clouds during cold air outbreaks, Bound-lay. Meteorol., 118, 557-581, https://doi.org/10.1007/s10546-005-6434-4, 2006.

410 Lüpkes, C. and Schlünzen, K. H.: Modelling the Arctic convective boundary-layer with different turbulence parameterizations, Bound-lay. Meteorol., 79, 107-130, https://doi.org/10.1007/BF00120077, 1996.

Lüpkes, C., Vihma, T., Birnbaum, G., Dierer, S., Garbrecht, T., Gryanik, V. M., Gryschka, M., Hartmann, J., Heinemann, G., Kaleschke, L., Raasch, S., Savijärvi, H., Schlünzen, K. H., and Wacker, U.: Mesoscale modelling of the Arctic atmospheric boundary layer and its interaction with sea ice, in: Arctic Climate Change, pp. 279-324, Springer, 2012.

Lüpkes, C., Hartmann, J., Schmitt, A. U., Birnbaum, G., Vihma, T., and Michaelis, J.: Airborne and dropsonde measurements in MCAOs during STABLE in March 2013. PANGAEA [data set], https://doi.org/0.1594/PANGAEA.936635, $2021 \mathrm{a}$.

Lüpkes, C., Hartmann, J., Schmitt, A. U., and Michaelis, J.: Convection over sea ice leads: Airborne measurements of the campaign STABLE from March 2013. PANGAEA [data set], https://doi.org/10.1594/PANGAEA.927260, 2021b.

Martin, C. and Suhr, I.: NCAR/EOL Atmospheric Sounding Processing ENvironment (ASPEN) software. Version 3.4.6. Available Online: https://www.eol.ucar.edu/content/aspen, Last access: May 20, 2021, 2021.

Michaelis, J., Lüpkes, C., Schmitt, A. U., and Hartmann, J.: Modelling and parametrization of the convective flow over leads in sea ice and comparison with airborne observations, Q. J. Roy. Meteor. Soc., 147, 914-943, https://doi.org/10.1002/qj.3953, 2021.

Pithan, F., Svensson, G., Caballero, R., Chechin, D., Cronin, T. W., Ekman, A. M., Neggers, R., Shupe, M. D., Solomon, A., Tjernström, M., and Wendisch, M.: Role of air-mass transformations in exchange between the Arctic and mid-latitudes, Nat. Geosci., 11, 805-812, https://doi.org/10.1038/s41561-018-0234-1, 2018.

Rasmussen, E. A.: Polar lows, in: A Half Century of Progress in Meteorology: A Tribute to Richard Reed, pp. 61-78, Springer, 2003.

Spreen, G., Kaleschke, L., and Heygster, G.: Sea ice remote sensing using AMSR-E 89-GHz channels, J. Geophys. Res.-Oceans, 113, https://doi.org/10.1029/2005JC003384, 2008.

Tetzlaff, A.: Convective processes in the polar atmospheric boundary layer: a study based on measurements and modeling, Doctoral dissertation, University of Bremen, Germany, 136 pp. Retrieved from http://nbn-resolving.de/urn:nbn:de:gbv:46-00105016-14., 2016.

Tetzlaff, A., Lüpkes, C., Birnbaum, G., Hartmann, J., Nygard, T., and Vihma, T.: Brief Communication: Trends in sea ice extent north of Svalbard and its impact on cold air outbreaks as observed in spring 2013, The Cryosphere, 8, 1757-1762, https://doi.org/10.5194/tc-81757-2014, 2014. 
https://doi.org/10.5194/essd-2021-341

Preprint. Discussion started: 3 November 2021

(c) Author(s) 2021. CC BY 4.0 License.

(c) (1)

Tetzlaff, A., Lüpkes, C., and Hartmann, J.: Aircraft-based observations of atmospheric boundary-layer modification over Arctic leads, Q. J.

Roy. Meteor. Soc., 141, 2839-2856, https://doi.org/10.1002/qj.2568, 2015.

Vaisala: Vaisala Dropsonde RD93, www.vaisala.com, 2009.

Vance, A. K., Taylor, J. P., Hewison, T. J., and Elms, J.: Comparison of in situ humidity data from aircraft, dropsonde, and radiosonde, J. Atmos. Ocean. Tech., 21, 921-932, https://doi.org/10.1175/1520-0426(2004)021<0921:COISHD>2.0.CO;2, 2004.

Vihma, T., Pirazzini, R., Fer, I., Renfrew, I. A., Sedlar, J., Tjernström, M., Lüpkes, C., Nygård, T., Notz, D., Weiss, J., Marsan, D., Cheng, B., Birnbaum, G., Gerland, S., Chechin, D., and Gascard, J. C.: Advances in understanding and parameterization of small-scale physical processes in the marine Arctic climate system: a review, Atmos. Chem. Phys., 14, 9403-9450, https://doi.org/10.5194/acp-14-9403-2014, 2014.

Vömel, H., Young, K., and Hock, T.: NCAR GPS Dropsonde Humidity Dry Bias, Tech. rep., National Center for Atmospheric Research Boulder, Colorado, 10 pp., https://www.aoml.noaa.gov/hrd/Storm_pages/Dropsonde_Dry_Bias_TN_531.pdf, 2016.

Vömel, H., Goodstein, M., Tudor, L., Witte, J., Fuchs-Stone, Ž., Sentić, S., Raymond, D., Martinez-Claros, J., Juračić, A., Maithel, V., and Whitaker, J. W.: High-resolution in situ observations of atmospheric thermodynamics using dropsondes during the Organization of Tropical East Pacific Convection (OTREC) field campaign, Earth Syst. Sci. Data, 13, 1107-1117, https://doi.org/10.5194/essd-13-11072021, 2021.

Wang, J., Bian, J., Brown, W. O., Cole, H., Grubišić, V., and Young, K.: Vertical air motion from T-REX radiosonde and dropsonde data, J. Atmos. Ocean. Tech., 26, 928-942, https://doi.org/10.1175/2008JTECHA1240.1, 2009.

Zahn, M. and von Storch, H.: Decreased frequency of North Atlantic polar lows associated with future climate warming, Nature, 467, 309-312, https://doi.org/10.1038/nature09388, 2010. 